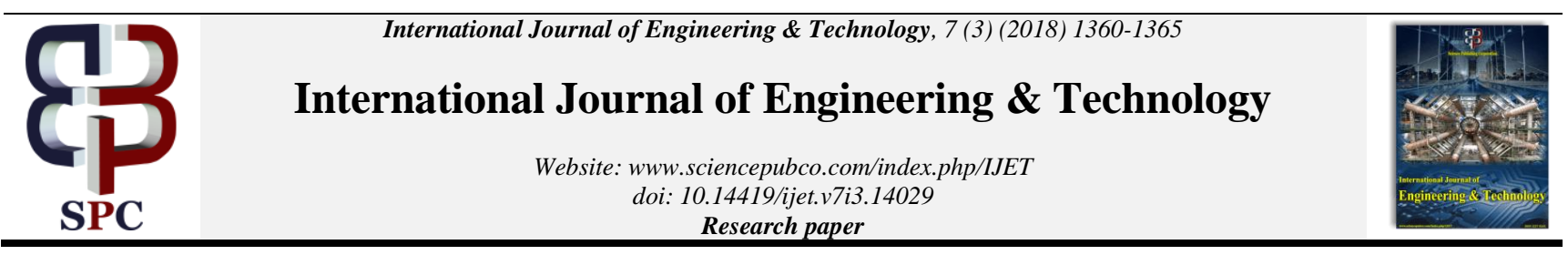

\title{
Role of academia-industry collaboration in enriching engineering education: A case study in sub-sahara context
}

\author{
Agarwal A. ${ }^{1}$, Seretse O. M. ${ }^{1}$, Letsatsi M. T. ${ }^{2}$, Marumo R. ${ }^{1}$, Mokgwathi. ${ }^{3}$ \\ ${ }^{1}$ Department of Mechanical Engineering, Faculty of engineering \& technology, University of Botswana, Gaborone. Botswana \\ ${ }^{2}$ Department of Industrial design and technology, Faculty of engineering \& technology, University of Botswana, Gaborone. Botswana \\ ${ }^{3}$ Mechanical Engineer, Botswana Power corporation, Botswana \\ *Corresponding author E-mail: agarwala@ub.ac.bw
}

\begin{abstract}
Education and training stays one of the key parts of technical institutions, particularly in sub-Sahara nations where the absence of talented laborers is a noteworthy bottleneck impeding the intensity and imaginative limit of firms. Building instruction is deficient with regards to an association amongst information and certifiable issues. Building training as a human undertaking is likewise confronting various extra difficulties of securing, and reception of information, advancement and innovation exchange, fortifying the instructive venture and occupation manifestations. Abilities improvement has been, and still is, an argumentative issue in the scholarly world and in addition mechanical segment. Presently days, the greater part of the universities are confronting the issue of absence of viable learning and experience among their lecturers who have joined the instructing soon after completing their graduation. This paper talks about the necessity of a compelling collaboration amongst the scholarly world and industry which has turned into an undeniably a basic part of productive national development frameworks. Industry encounter enables instructive projects to grow in inventive ways. The contextual investigation examined, demonstrates that such collective endeavors can prompt expanded organization with researchers from various and interdisciplinary foundations.
\end{abstract}

Keywords: Academics; EEEP; Partnership; Education Curriculum; Skill Development.

\section{Introduction}

Botswana is a landlocked nation in Southern Africa that outskirts the nations of Namibia, South Africa, Zimbabwe, and Zambia as shown in figure 1 below. The geology is level, and up to $70 \%$ of Botswana is secured by the Kalahari Desert, in this way making it a meagerly populated nation with minimal horticultural action. The administration framework is a parliamentary republic; the head of state and head of government is the president. Botswana has a blended monetary framework, which incorporates an assortment of private opportunity, joined with unified financial arranging and government control. Botswana is an individual from the Southern African Development Community (SADC). [1]

Sparsely populated Botswana's property region is bigger than Spain and overwhelmed by the immense Kalahari Desert. Botswana has bounteous precious stone and other characteristic assets, a market-situated economy, and one of Africa's most astounding sovereign FICO scores. To differentiate the economy through tourism, Botswana centers on protection and advancement of its broad nature preserves.

Exchange, Trade is critical to Botswana's economy; the consolidated estimation of fares and imports levels with 106 percent of GDP.

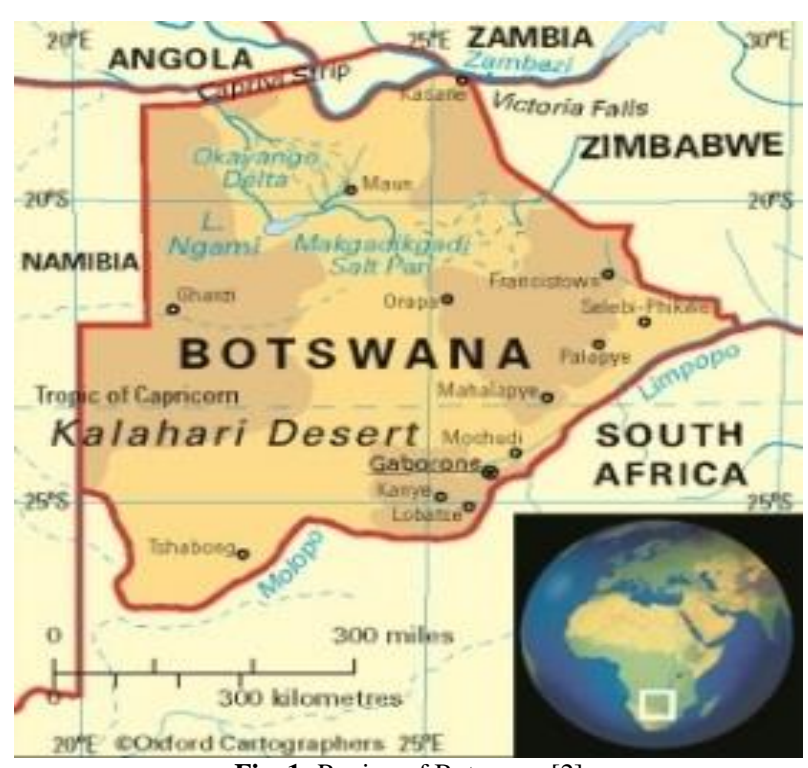

Fig. 1: Region of Botswana [2]

The normal connected duty rate is 0.5 percent. Nontariff hindrances block exchange. Botswana is a piece of the Southern African Customs Union (SACU) with South Africa, Lesotho, Swaziland, and Namibia. The World Bank reports that in 2001 (the latest year for which World Bank information are accessible), the SACU had 
a weighted normal regular outside duty rate of 3.6 percent. As indicated by the U.S. Division of Commerce, "there are not very many duty or non-levy boundaries to exchange with Botswana, aside from confinements on authorizing for some business tasks, which are held for [Botswana] organizations." Based on the updated exchange factor approach, Botswana's exchange strategy score is unaltered. Noteworthy mineral (precious stone) riches, great administration, judicious financial administration and a moderately little populace of in excess of two million, have made it an upper center pay nation. The World Bank's commitment is centered on helping it combine its encouraging while at the same time tending to a scope of tireless and rising difficulties. The principle fare of Botswana is precious stones. Starting at 2017 it is the world's second biggest maker of precious stones after Russia. Because of Botswana's overwhelming dependence on precious stones, solid worldwide request is imperative to the soundness of the economy. Precious stone fares give Botswana's economy solid supplies of outside trade and have offered a reason for mechanical advancement and fortified enhancements in Botswana's foundation. In any case, notwithstanding their overwhelming part in Botswana's economy, there are worries that jewel mines are not work escalated enough to give adequate work to Botswana's workforce, and this jumble has been referred to as a factor in the nation's fundamentally high joblessness rate. [3] Government receptiveness to outside venture is better than expected. The little yet energetic money related part energizes financial expansion. Private-area access to credit is kept up viably by the keeping money part and well-working capital markets. Botswana's monetary flexibility score is 69.9 , making its economy the 35th freest in the 2018 Index. Its general score has diminished by 0.2 point, with bring down scores for the work flexibility, financial wellbeing, and taxation rate markers exceeding enhancements in government spending and fiscal opportunity. Botswana is positioned second among 47 nations in the Sub-Saharan Africa area, and its general score is over the territorial and world midpoints. Through financial teach and sound administration, Botswana has changed itself from one of the world's poorest nations to a center wage nation. Financial approach is guided by the administration's endeavors to enhance the economy far from reliance on the unstable mining part and toward horticulture, administrations, and assembling. The administrative condition empowers development, and receptiveness to outside speculation and exchange advances aggressiveness and versatility. [4] In spite of Botswana's monetary development, the nation faces large amounts of neediness and disparity, particularly in provincial regions and the southern piece of the nation. It is relied upon to gain moderate ground on neediness lessening over the medium-term, with destitution tumbling to around $16 \%$ as per the 2015/16 Multi-Topic Household Survey. Quickening neediness decrease will require strong choices that energize more prominent private segment work creation, higher esteem included horticultural generation and administrations, credit extension, and lower family unit obligation. While Botswana's social division uses have been liberal, they have not yielded the effect one may anticipate. Instruction use is among the most elevated on the planet around 9\% of GDP - and incorporates the arrangement of almost general free essential training, however has not made a talented workforce. Joblessness has remained wilfully high at $17.7 \%$ and Botswana's wage imbalance is one of the most elevated on the planet. [5].

\section{Education system in botswana}

The instructive structure in Botswana reflects that of the United Kingdom: there is all inclusive access to essential and junior optional school, yet a procedure of scholarly selectivity decreases access to the senior auxiliary school and the college. In any case, instructive educational program consolidates prevocational arrangement in the lesser and senior optional schools. Botswana's legislature is making instruction one of its best needs, wanting to increment instructive open doors for ages to come. The Ministry of Botswana Education has been completing an admirable activity since the autonomy of the nation. The Ministry of Botswana Education oversees the general development in the quantity of understudies of all phases in Botswana. [6] In 2001 Botswana's training framework was contained seven long periods of essential instruction, three long stretches of junior auxiliary instruction, and two long periods of senior optional training. Every year at the essential level is a Standard, and every auxiliary level is a Form. This framework was executed in 1995 because of a 1993 National Education Commission ponder. Botswana's fundamental instruction program is included the essential and junior optional levels. About 86 percent of the youngsters in Botswana go to elementary school, yet that rate drops to only 35 percent of kids who go to auxiliary school. [6] The administration endeavors to make all level of training available to everybody. One focal goal of essential instruction is for kids to be proficient first in Setswana and after that in English. Different objectives are for kids to end up educated in arithmetic and to have an order of science and social investigations. From 1991 to 1997, the quantity of understudies finishing the essential level and entering junior auxiliary expanded from 65.0 percent to 98.5 percent. Finishing the Junior Certificate program may prompt admission to the senior auxiliary school program. Just those students whose evaluations are sufficiently high on the Junior Certificate Examination are admitted to the senior optional program. From 1991 to 1994, the quantity of understudies admitted to senior optional schools expanded from 28 to 34 percent. Botswana is building brought together auxiliary schools, Form I to Form V, in the remote zones of the nation to expand access to a senior optional instruction. [7]. There are an assortment of tertiary training foundations in Botswana, including schools of bookkeeping and farming, and organizations of organization, business, and wellbeing sciences. Instruction has been given need in the national spending plan. In the 1994-1995 budgetary year, the Ministry of Education got 10 percent of the national spending plan. The Department of Secondary Education and Teacher Training and Development shared 64 percent, and the service central station, which oversaw four ventures including the University of Botswana and Brigades advancement, got 25 percent. The 11 percent adjust was spent on enhancing offices and capacities under the specialized training, non-formal instruction, educational programs advancement, and assessment and custom curriculum offices. The Ministry of Education extended from a little unit of government in 1966 to one that takes care of the instructive needs of many thousands understudies from essential to tertiary levels. Moreover, the service composes every single required course book. The service's accentuation is on preparing qualified instructors, building up an enhanced educational programs, and growing offices to meet the national responsibility of widespread training. Table 1 shows the governmental education bodies in the country.

Table 1: Education Scenario in Botswana [8] [9] Institutions Technical Colleges 
Botswana College of Open and Distance Learning (BOCODOL)

(Now, Botswana Open University)

Botswana Innovation Hub (BIH).

Botswana Institute for Technology, Research and Innovation

(BITRI).

Botswana International University of Science and Technology (BIUST).

Botswana Qualification Authority (BQA).

Human Research Council (HRDC).

University of Botswana (UB).

Botswana University of Agriculture and Natural Resources (BUAN)
Gaborone Technical College.

Jwaneng Technical College.

Maun Technical College.

Oodi College of Applied Arts and Technology.

Palapye Technical College.

Selebi Phikwe Technology College.

Francistown College of Technical and Voca-

tional Education (FCTVE).

\section{Engineering education at university of bot- swana}

University of Botswana was initially started as a part of the University of Bechuanaland (Botswana), Basutoland (Lesotho), and Swaziland. After Botswana and Lesotho ended up free in 1966, the college was known as the University of Botswana, Lesotho, and Swaziland (UBLS). In 1975 Lesotho pulled back from the association and built up its own national college. For quite a long while a joint University of Botswana and Swaziland existed until in the mid-1980s the college was agreeably isolated into two separate national colleges. The University is firmly engaged with the national advancement procedure of Botswana. In such manner the exceptional elements of the University are to take part in enhancing the quality and in extending the amount of the HR required for improvement, and to go about as the vault of the aggregate information and experience of the country and the world. The first of these capacities is satisfied through the instructing programs offered by the University and its partnered foundations, prompting the honor of degrees, confirmations and declarations. The second capacity is done exclusively, and all things considered by the staff of the University and its partnered foundations, through the innovative work, consultancies and data administrations which they undertake. [10] The college has three grounds: one in the capital city Gaborone, one in Francistown, and another in Maun. The college is partitioned into six resources: Business, Education, Engineering, Humanities, Science and Social Sciences. The faculty of engineering and technology (FET) at University of Botswana has five departments namely Architecture and Planning, Civil Engineering, Electrical Engineering, Industrial Design and technology and Mechanical Engineering. The aim of faculty is to produce high quality Engineering graduates who will be able to adapt to the working environment and to discharge their duties to the satisfaction of their employers. There are different program running under the faculty eg. B.Engg, M.Engg. , M.Phil \& Doctoral Programs. Research and innovation is the primary focus area of the faculty.

\section{Requirement of university- industry part- nership}

The aptitudes lack in the scholarly world and modern areas is one of the principle hindrances to achieving the administration's expressed financial development targets. This has made aptitudes improvement critical to nation's development and advance. Thus, there are mainly two types of shortage of skills-

1) An engineering teacher or lecturer without having practical and industrial knowledge, training.

2) An industry worker without having technical and implementation abilities.

The first is the significant issue among the designing instruction part. Now and again, they are additionally alluded as conceived educators. Some portion of the issue is that training posts are being filled by new graduates as a methods for financing further examination. 'There is genuine worry inside the building calling that an expanding number of advanced education staff encouraging designing have no industry information or experience. Numer- ous building graduates that proceed with their advanced education studies and research exercises full time have no choice other than to acknowledge training presents on finance their scholarly vocations. 'Subsequently some advanced education staff have no enthusiasm for instructing and this shows itself in a poor learning knowledge for students. Across sub-Saharan Africa building aptitudes deficiencies are common, and understudies are selecting in designing courses wanting to fill this hole. However repeatedly, obsolete gear and showing strategies at advanced education foundations imply that these understudies graduate without the aptitudes and down to earth encounter expected to thrive in buildingbased enterprises. It is critical to comprehend the genuine building exercises required in mechanical division and to consider them in a monetary setting as an esteem demonstrate, towards the effective execution of hierarchical system in fulfilling client needs. The perspective of value in building exists in two particular ideal models; the apparent estimation of the examination, and the qualities inborn inside the mechanical aptitude. These are moderately synonymous with the conveyance procedure of value ordinarily connected in any framework. College industry linkages have essentially turned out to be a standout amongst the most imperative motivation of advanced education approach making, and also in the monetary condition of both the national and institutional levels. With regards to information concentrated economies, the significance of higher establishments of learning as key performing artists in both national and local monetary advancement can't be belittled given their capability to update aptitudes and learning of the work compel and contribute towards delivering and handling development through innovation exchange notes.[11] Saad and Zawdie contended the circles of government, college and industry are required to be connected through three interrelated components to each other so as to upgrade the level of learning and advancement in a particular nation. These three linkages comprise of:

- The movement connect (specialized, regulatory, business and different exercises of an association)

- The asset interface (accessibility and availability of assets significantly affects the nature of the relationship).

- The on-screen characters interface (connections and practices).

Because of these collaborations, more noteworthy trust and cooperative energy inside the relationship will be produced as shown in figure 2. The last level is perceived as a pre-imperative for the achievement of the Triple Helix college industry-government demonstrate. [12] 


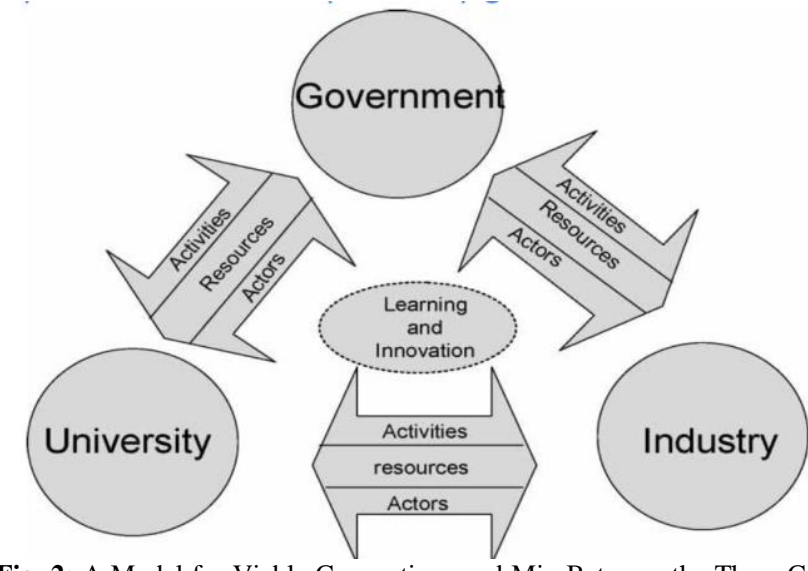

Fig. 2: A Model for Viable Connections and Mix Between the Three Circles of the Triple Helix Model [12].

Advanced education assumes a key part in science-development biological communities, which are established on the creation, exchange and use of cutting edge learning and aptitudes. The exploration escalated colleges unite imagination, ability, and other imperative assets to take part in logical research. One of the numerous manners by which colleges are reacting to worldwide rivalry and change is through the fuse of college industry joint efforts and organizations into their projects. College industry linkage is viewed as a noteworthy communitarian exertion with respect to the two unmistakable elements, the scholarly world and industry that offer their assets in a powerful and proficient route for achieving commonly good objectives of mechanical development, upgrading worldwide intensity and executing as motor for financial development. [11] On the other hand, the college graduates ought to have presentation and experience of the handy work life, which will go about as a take-off platform for their future expert professions. [13] According to [14], collaboration gives great learning chances to endeavors, and undertakings should center not just around particular advancements, procedures or items bringing here and now benefits yet additionally on proceeding to learn through participation with colleges. The colleges in Britain and American were firmly connected to enterprises. The collaboration has been reinforced by enactment in America and industry joins had been disentangled through participation in Britain. [15]. Writing audit demonstrates that, the college business joint efforts and organizations affect the teaming up establishments. Development progressively relies upon the capacity of college and industry specialists to cooperate over various orders, for example, innovation, plan and designing. Empower multidisciplinary scholastic projects and advance the commitment of industry in such projects.

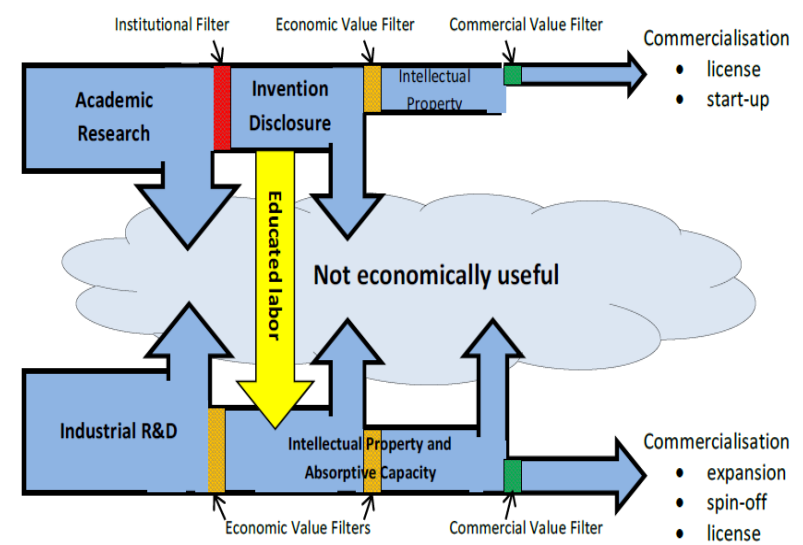

Fig. 3: Knowledge Filter Model of University-Industry Commercialisation [16].

A learning channel share demonstrate introduces in figure 3 demonstrates a streamlined picture of college industry interconnections - as far as how information usage spaces and effect pathways may communicate - from an exploration commercialization point of view. A progression of basic leadership forms sift through promising thoughts and results, figure out what traverses college/industry limits, and at last what may turn out to be financially helpful development [16]. Likewise, Botswana's vision of 2036 lines up with the worldwide plan for maintainable improvement and the standards of Africa motivation 2063, to guarantee that the nation seek after the national yearnings in a way that empowers Botswana to meet the worldwide and provincial objectives. College of Botswana is broadly seen as a financial motor that can decidedly add to a nation's development notwithstanding its essential part as a middle for learning. Be that as it may, for college to keep up an upper hand in a learning society where inventiveness and developments are at middle of everyone's attention. Another vision ought to be incorporated delivering the exceedingly gifted workforce for a comprehensively aggressive economy. The college ought to be seen not similarly as a generator of thoughts but rather as a wellspring of information and ability that can profit society.

\section{Overview of enriching engineering educa- tion program in sub-Sahara African nations}

The Enriching Engineering Education Program is controlled by the Royal Academy of Engineering as a major aspect of its work focused at supporting and praising the up and coming age of worldwide specialists and building institutional limit universally. The program is kept running with the liberal help of the AngloAmerican Group Foundation. The Enriching Engineering Education Program is fixated on a blend of two way secondments and synergistic workshops. These secondments and workshops have prompted enhanced industry-the scholarly world connections and brought about far reaching benefits for the two gatherings, for instance by adjusting the educational modules all the more intently to national and provincial advancement needs. [17] The vital point of the undertaking is to enhance the standard of designing instruction in Botswana and the district through building organizations with industry. This point will be accomplished through the accompanying particular goals: [18]

- To manufacture fruitful organizations amongst industry and scholastic foundations broadly and territorially through information sharing, staff connections and visitor addresses.

- To secure industry connection for training staff to encourage abilities obtaining.

- To set up and fortify departmental warning sheets to affect industry important projects.

- To draw in industry experts in giving visitor addresses, courses, proficient advancement workshops and move understudies through handy experiences in the work environment.

\subsection{Case study staff secondment at coal fired thermal power plant}

The author served a secondment at Morupule A power plant in March 2018, to think about various warm building forms and watching genuine designing practices in the region of energy age, quality confirmation and Breakdown upkeep and to contemplate/watch their procedures to recognize the holes or degree for warm investigation and working of a power plant, turbines, compressors, pumps, heater and so forth for development expected to enhance the distinctive related procedures. Likewise, to recognize and wipe out any type of abundance amid support assessment hone. As shown in reference figure 4, the Morupule A power plant is under refurbishment condition, so it was a decent chance to comprehend the diverse procedures intently and take in the genuine building work. The connection begins with getting an entering permit and after that a SHE enlistment by Safety and wellbeing office, which is an essential necessity before entering to the power plant. The energizing knowledge and introduction to the power 
business causes us to acknowledge how the hypothesis they are shown mixes with training. Besides, an enlightening part is the taking care of the emerging building issues and how they are comprehended and furthermore the support of the plant machines

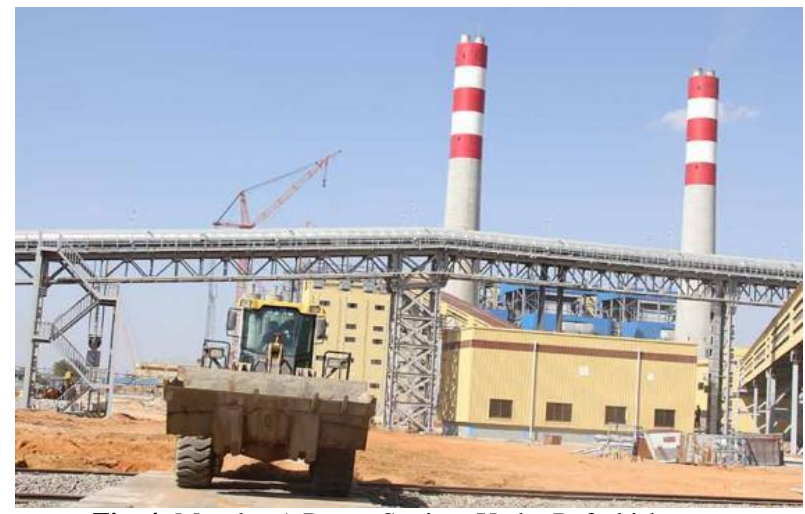

Fig. 4: Morulae A Power Station- Under Refurbishment.

\subsection{About the industry}

Botswana Power Corporation (BPC); a state possessed organization is associated with electrical power age, transmission and appropriation in Botswana. It was built up in 1970 and is at present the main power provider in the nation. It expressed by authorizing a little oil-let go control station in Gaborone and later a greater one was worked in Selebi Phikwe however disassembled it in 1989. It moved to a warm power station usually known as Morupule A which is found nearly $12 \mathrm{~km}$ west of Palapye town in the focal region. The Power station is provided with coal from nearby Morupule Colliery. Neighboring Morupule A, Morupule B control station was set to end intense lack of energy in Botswana. It has four $150 \mathrm{MW}$ units hence creating a sum of $600 \mathrm{MW}$ when contrasted with 132MW delivered by Morupule A power station. The power plant, which has been closed down since 2012, has an aggregate limit of 132 megawatts including four generators creating 33 megawatts. Under the agreement, Doosan Heavy Industries and Construction will supplant and repair turbines and boilers in the Morupule A power plant.

\subsection{Study and knowledge sharing}

The Morupule A power station uses coal as fuel which is from the Morupule colliery mine. Coal is a mineral possessing chemical Energy. Carbon made from ancient plant material gives coal most of its energy. This chemical energy is released in a process to generate Electricity. The steps involved in the conversion of coal to electricity are;

- Transportation of (fuel) coal to plant stock yard.

- Preparation of (fuel) coal suitable for combustion in boiler to generate heat.

- $\quad$ Preparation of heat carrying medium (WTP).

- Heat transfer to heat carrying medium(water/steam)

- Heat transfer by Conduction, Convection, Radiation, (Boiler)

- $\quad$ Converting heat energy to mechanical energy, (Turbine)

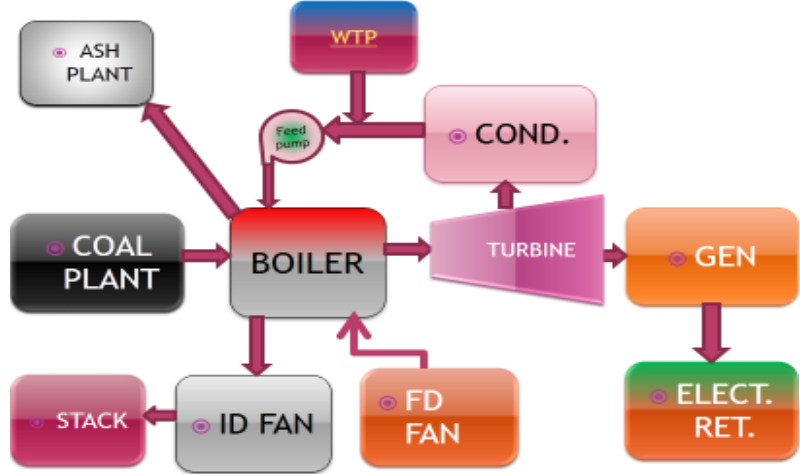

Fig. 5: Thermal Power Plant Plant Overview.

Converting mechanical energy to electrical energy, (Alternator) Even though the plant is still undergoing refurbishment works, author has covered most of the crucial areas that would be of benefit to my study. The Plant Areas that were covered included but not limited to the following:

- Boiler Plant area covering all Boilers and Milling system (Coal Pulverisers).

- Turbines including the newly installed Turbine 3 by Skoda Power

- $\quad$ Flue Gas Desulphurization Plant (FGD)

- Ash Handling Plant

- Water Treatment Plant where you were able to appreciate water chemical analysis

- Main Central Control Room for plant operation processes.

- Main Plant Compressor System

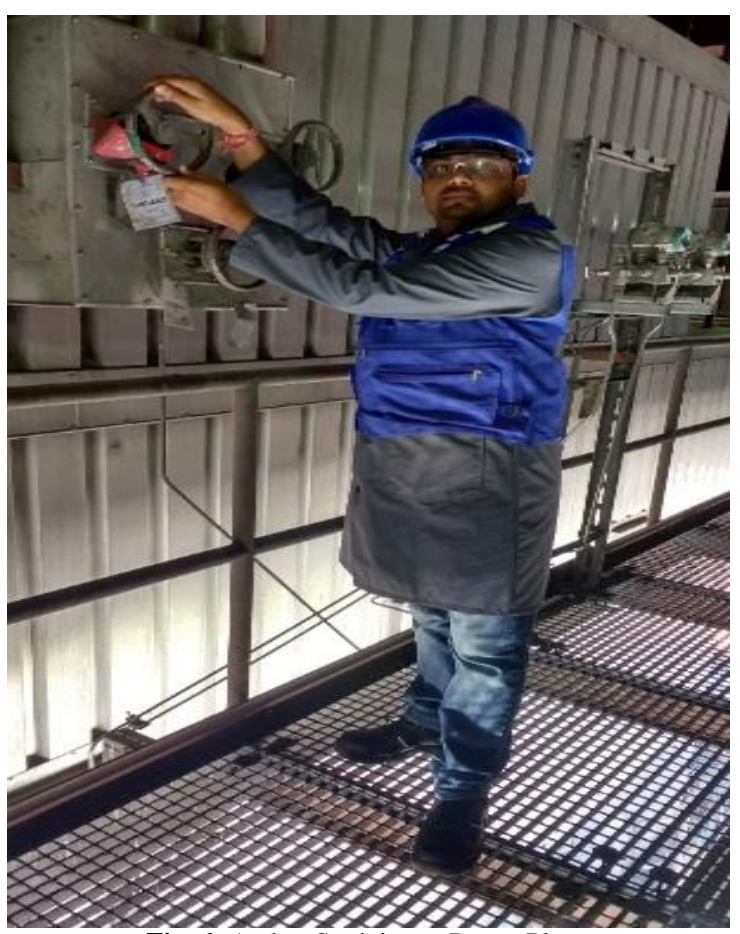

Fig. 6: Author Studying at Power Plant.

Author was able to appreciate and analyse thermal heat transfer calculations for our boilers and turbines which were verified with design calculations. As stated before, the FGD system is a new concept with intention of greatly minimizing effects of pollution from burning coal and abide by the World Bank standards for Power Plants. The system uses dry sodium Bicarbonate as compared to wet systems employed in most modern Power Plants obvious reason for this is that water is scarce in Botswana so a dry method was more suitable. The study also covered the Newly Installed coal Mills that are designed specifically to interface with Low NOx Burners which are also newly installed. The whole idea is to minimize NOx emission from the combustion system and 
improve on pollution control just like the FGD. The analysis show that the coal from the mine is of significant caloric value approx. $23 \mathrm{MJ} / \mathrm{kg}$ rated and in line with the plant design efficiency. The tube failure analysis that he did together with Mechanical Engineer for replaced tubes which were found in Boilers 1 and 4 showed that from our observation, creep failure due to excessive temperatures was most probable cause and my advice to check for tube thickness on every outage inspection is definitely come in handy.

\section{Implementation \& feedback}

We implemented the knowledge and experience learned during the secondment served at thermal power plant in the teaching of the course 'Thermal fluid system design' \& 'Final year projects, which are core final year mechanical engineering courses at University of Botswana, through various seminars, presentations, lectures and tutorials involving design, processing \& overhauling of steam turbines, pumps, compressors and different Boiler mountings, accessories.

Although the objectives of the secondment were of a wide variety it is worth noting that there are a few aspects that make a successful engineering guy. Understanding communication, interpersonal skills and protocol is quite vital as it can lead to high professionalism. Being able to integrate engineering theory to solve practical problems is the most import aspect in being a good engineer. The practical knowledge sharing session were greatly appreciated by students. A web based survey of course curriculum and structure shows the result average of 4.33 on scale of 5 which is a great achievement toward student satisfaction and industry oriented growth.

\section{Conclusion}

Great courses pull in students and researchers, yet they are not generally the best set to judge the nature of their educating. They will judge the nature of instructing around the between individual aptitudes of individual educating staff. They would be unconscious if encouraging staff are out of venture with current designing practice utilized inside industry. 'Unmistakably, where understudies appreciate a decent learning background their input will help pull in different understudies to think about the subject; be that as it may, once more, a great encouraging knowledge could be out of advance with industry and will just end up obvious when understudies graduate and look for work inside industry. [19] The investigation visit and connection with Morupule A power station has unquestionably given such aptitudes. Handy ramifications, certainty and activity critical thinking of mechanical issues were one of the aptitudes gained. This scholarly community industry association is an intercession to enhance the nature of building instruction at the University of Botswana through the Enriching Engineering Education Program (EEEP) whose point is to guarantee that the advanced education framework in Sub-Saharan Africa produces engineers with the aptitudes and information required to address the issues of industry and to handle neighborhood challenges. The most proper way to deal with advancing scholarly world industry joint effort relies upon the nation's mechanical and institutional enrichments and its readiness to consider the advancement of college industry linkages as a component of a more extensive science, innovation, and development arrangement program.

\section{Acknowledgement}

Authors are grateful to EEEP project to provide necessary funding for the study, the hub university project coordination team and BPC officers for providing necessary support to carry out this work.

\section{References}

[1] A. Agarwal, O.M. Seretse, M.T. Letsatsi, E. Dintwa (2018); Review of Energy Status and Associated Conservational Issues in Botswana; MATEC Web of Conferences; issue 172; article 06003; https://doi.org/10.1051/matecconf/201817206003.

[2] "The commonwealth/botswana," 2018. [Online]. Available: http://thecommonwealth.org/our-member-countries/botswana. [Accessed: 25-Nov-2017].

[3] "Economy of Botswana," 2017. [Online]. Available: https://en.wikipedia.org/wiki/Economy_of_Botswana. [Accessed: 12-Dec-2017].

[4] "Botswana," $2018 . \quad$ [Online]. Available: https://www.heritage.org/index/country/botswana. [Accessed: 08Jun-2018].

[5] "The World Bank in Botswana/Context," 2018. [Online]. Available: http://www.worldbank.org/en/country/botswana/overview. [Accessed: 19-Apr-2018].

[6] A. Grote, "Education in Botswana." [Online]. Available: https://borgenproject.org/education-botswana/. [Accessed: 31-Mar2016].

[7] "Botswana - Educational System-overview." [Online]. Available: http://education.stateuniversity.com/pages/186/BotswanaEDUCATIONAL-SYSTEM-OVERVIEW.html. [Accessed: 16Aug-2017].

[8] "Ministry of Education and Skills Development." [Online]. Available:

https://en.wikipedia.org/wiki/Ministry_of_Education_and_Skills_D evelopment. [Accessed: 05-Feb-2018].

[9] BOPA, "President re-organises, re-designates ministries," 2016. [Online]. Available: http://www.dailynews.gov.bw/newsdetails.php?nid=31271. [Accessed: $28-$ Sep-2016].

[10] "About UB." [Online]. Available: https://www.ub.bw/about-ub. [Accessed: 01-Apr-2017].

[11] D. W. Tumuti, P. M. Wanderi, and C. L. Thoruwa, "Benefits of University-Industry Partnerships: The Case of Kenyatta University and Equity Bank.” Int. J. Bus. Soc. Sci., vol. 4, no. 7, pp. 26-33, 2013.

[12] A. A. Razak and M. Saad, "The role of universities in the evolution of the Triple Helix culture of innovation network: The case of Malaysia.” Int. J. Technol. Manag. Sustain. Dev., vol. 6, no. 3, pp. 211-225, 2007. https://doi.org/10.1386/ijtm.6.3.211_1.

[13] G. Edmondson, L. Valigra, M. Kenward, R. L. Hudson, and H. Belfield, "MAKING INDUSTRY-UNIVERSITY PARTNERSHIPS WORK Lessons from successful collaborations," Bus. Innov. Board AISBL, pp. 1-52, 2012.

[14] R. M. Cyert and G. P. S., "Creating effective university-industry alliances: an organizational learning perspective." Organ. Dyn. vol. 25, no. 4, pp. 45-57, 1997. https://doi.org/10.1016/S00902616(97)90036-X.

[15] M. H. Decter, "Comparative review of UK-USA industryuniversity relationships," Educ. + Train. vol. 51, no. 8/9, pp. 624 634, 2006. https://doi.org/10.1108/00400910911005190.

[16] B. Carlsson, J. A. Zoltan, and A. David B., "The Knowledge Filter, Entrepreneurship, and Economic Growth,” JENA Econ. Res. Pap. Friedrich-Schiller-University Jena, Max-Planck-Institute Econ., vol. 57, 2007.

[17] R. A. of Engineering, "Enriching Engineering Education Programme."

[18] E. M. Sebusang and J. Gandure, "Enriching Engineering Education: Botswana Perspective," in BIE Biannual International Conference, 2017.

[19] J. Excell, "Academia's engineering skills shortage," The engi$\begin{array}{lll}\text { neer.co.uk, 2013. } & \text { [Online]. }\end{array}$ https://www.theengineer.co.uk/issues/december-2013online/academias-engineering-skills-shortage/. [Accessed: 26-Jan2017]. 